\title{
Activity of antibacterial protein from maggots against Staphylococcus aureus in vitro and in vivo
}

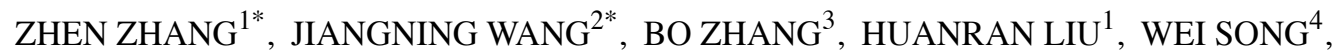 \\ JIAO HE ${ }^{1}$, DECHENG LV ${ }^{1}$, SHOUYU WANG ${ }^{1}$ and XIAOGUANG XU ${ }^{5}$
}

\author{
${ }^{1}$ Department of Orthopedic Surgery, The First Affiliated Hospital of Dalian Medical University, Dalian 116011; \\ ${ }^{2}$ Department of Reparative and Reconstructive Surgery, Luhe Hospital, Capital Medical University, Beijing 101100; \\ Departments of ${ }^{3}$ Neurosurgery and ${ }^{4}$ Clinical Laboratory, The First Affiliated Hospital of Dalian Medical University, \\ Dalian 116011; ${ }^{5}$ Department of Neurosurgery, The Second Affiliated Hospital of \\ Dalian Medical University, Dalian 116027, P.R. China
}

Received December 13, 2012; Accepted February 15, 2013

DOI: $10.3892 /$ ijmm.2013.1291

\begin{abstract}
Maggots (larvae of Lucilia sericata) have shown therapeutic effects on refractory wounds infected with bacteria, yet the bacterial killing mechanisms are unclear. Herein, we report the isolation and purification of an antibacterial protein from maggots (MAMP). MAMP demonstrated inhibitory activity against both standard strains and clinically isolated antibiotic-resistant strains of Staphylococcus aureus in vitro. The topical use of MAMP effectively decreased the viability of $S$. aureus and promoted wound healing in an $S$. aureus mouse skin infection model. MAMP exerted its antibacterial activity via a bactericidal mechanism based on observations using scanning electron and transmission electron microscopy. MAMP interacted with the bacterial cell membrane and disrupted the cell surface structure. In addition, MAMP had weak hemolytic activity at a high concentration. Taken together, MAMP exhibits potential use as a topical agent for treating bacterial infections.
\end{abstract}

\section{Introduction}

Antibiotic resistance has become a serious and increasing threat to human health. For example, it is estremely difficult to treat infected wounds caused by antibiotic-resistant pathogens

Correspondence to: Dr Shouyu Wang, Department of Orthopedic Surgery, The First Affiliated Hospital of Dalian Medical University, 222 Zhongshan Road, Dalian 116011, P.R. China

E-mail: wangshouyu666@126.com

Dr Xiaoguang Xu, Department of Neurosurgery, The Second Affiliated Hospital of Dalian Medical University, Dalian 116027, P.R. China

E-mail: xuxg2007@sina.com

${ }^{*}$ Contributed equally

Key words: maggots, antibacterial protein, Staphylococcus aureus using common antibiotics (1). There is an urgent need for the development of new antibacterial agents. Natural product anti-infectious agents are attractive options.

Maggot (fly larva) therapy with the larvae of Lucilia sericata is an effective and simple method for cleaning infected and necrotic wounds (2-8). Its use dates back to the beginning of civilization, and it became popular and prevalent for the treatment of chronic or infected wounds worldwide during the 1930s (2). With the introduction and production of antibiotics in the 1940s, however, the academic and clinical interest in this biosurgery was unfortunately lost. In the 1990s the rising incidence of antibiotic resistance resulted in the renaissance of maggot therapy. Despite the repeated falling out of favor and the persistent public disdain which hamper its acceptance, the practice of maggot therapy is on the rise, attributed to its efficacy, safety and simplicity. Our group has performed successful maggot bio-debridement on diabetic foot ulcers, pressure ulcers after spinal cord injury and infected wounds after forearm replantation $(7,8)$. Sherman (3) and Mumcuoglu (4) have confirmed that maggot therapy benefits patients through rapid wound debridement and elimination of infection. Recently, there is an increasing interest in investigating antimicrobial protein from maggots (MAMP) that belongs to the family of antimicrobial peptides (AMPs). Several reports have described that the maggot contains a diversity of bioactive proteins with antimicrobial function, either in the whole body or in the excretion/secretion (9-11).

AMPs have broad-spectrum activity against a wide range of micro-organisms including viruses, Grampositive and Gram-negative bacteria, protozoa, yeasts and fungi $(12,13)$. However, the mechanisms of action for its effects on infected wounds remain unclear. Staphylococci are common commensal bacteria of the skin (14) and are also an important pathogen in foreign-pathogen infections (15). The Gram-positive Staphylococcus (S.) aureus is a major human pathogen of many nosocomial infections, including life-threatening diseases such as toxic shock syndrome, endocarditis and chronic infected wounds (16). The emergence of 
multidrug-resistant strains of $S$. aureus, such as methicillinresistant $S$. aureus (MRSA), has intensified the need for the development of new treatment modalities.

In the present study, we purified antimicrobial proteins from the body of maggots with ultrafiltration, and then investigated their in vitro and in vivo biological activities and the mechanisms of action on infected wounds caused by $S$. aureus. The results provide a basis for the further development of AMP-based therapy.

\section{Materials and methods}

Ethical considerations concerning the human subjects and animal use and care. The present study involving human participants was reviewed and approved by the Clinical Research Ethics Committee of Dalian Medical University, Dalian, China. Written consent was obtained from each of the participants who provided blood samples voluntarily for the study. All animal experiments were in accordance with the NIH Guide for the Care and Use of Laboratory Animals, and the protocols were reviewed and approved by the Committee on Research and Animal Care of Dalian Medical University.

Bacterial strains. S. aureus (ATCC 25923, 29213 and AB94004) was purchased from the China Center of Type Culture Collection. Clinical isolates were obtained from the Department of Clinical Laboratory, The First Affiliated Hospital of Dalian Medical University, including penicillinresistant $S$. aureus 12SAU130, penicillin-resistant $S$. aureus 12SAU133, methicillin-resistant $S$. aureus 12 SAU124 and methicillin-resistant $S$. aureus $12 \mathrm{SAU} 145$.

Crude protein extract from maggots. Eggs of L. sericata were collected from the eyes of Scomberomorus niphonius and were disinfected in $1 \%$ sodium sulfite solution for $3 \mathrm{~min}$, followed by $3 \%$ Lysol disinfectant for $5 \mathrm{~min}$. The disinfected eggs were transferred to sterile vials for cloning. The third stage L. sericata larvae were placed in 3.5\% methanol/normal saline solution for $5 \mathrm{~min}, 2 \%$ hydrogen peroxide solution for $3 \mathrm{~min}$, and $5 \%$ dilute hydrochloric acid solution for $5 \mathrm{~min}$. Following a two-step disinfection, larvae were homogenized by a mortar in precooling TAE buffer solution $(1: 3 \mathrm{v} / \mathrm{v})$. The homogenate was then centrifuged thrice at $12,000 \times \mathrm{g}$ at $4^{\circ} \mathrm{C}$, for $30 \mathrm{~min}$. The supernatant was collected and used as a crude protein extract.

Purification of the crude protein extract. The crude extract was primarily passed through a $30-\mathrm{kDa}$ cut-off ultrafiltration membrane on a Labscale ${ }^{\mathrm{TM}}$ TFF System (Millipore, USA). The filtrate was then ultrafiltrated by a 10-kDa cut-off ultrafiltration membrane, and the filtrate $(<10 \mathrm{kDa})$ and the cut-off fluid (10-30 kDa) were obtained for further testing.

Determination of protein concentration. The protein concentration was determined by the Bradford method (17) and bovine serum albumin (BSA) was used as the standard. The standard curve was established as follows: $y=0.0082 x-0.0035$ $\left(\mathrm{R}^{2}=0.9995\right)$ [where the $\mathrm{x}$-axis represents the protein concentration and the $y$-axis represents the optical density (OD)].
The final concentration of protein in subsequent assays was $50 \mu \mathrm{g} / \mathrm{ml}$.

\section{Antimicrobial assays in vitro}

Identification of the antimicrobial peptide from maggots (MAMP) using a turbidometric (TB) assay. The TB assay was modified from that of Thomas et al (18). S. aureus (ATCC 25923) was grown, washed in PBS and adjusted to a concentration of $10^{5}$ CFUs in fresh tryptic soy broth (TSB). The crude protein extracts, cut-off fluid or filtrate $(200 \mu \mathrm{l})$ were mixed, respectively, with $22 \mu \mathrm{l}$ of $10 \%$ peptone water and the $\mathrm{pH}$ was measured. One hundred and fifty milliliters of the samples was incubated with $30 \mu \mathrm{l}$ of the bacterial suspension in triplicate in a 96-well microtiter plate (Nunc; Fisher Scientific UK, Leicestershire, UK). Samples were incubated at $37^{\circ} \mathrm{C}$ for $24 \mathrm{~h}$, and the optical density at $589 \mathrm{~nm}$ (OD589) was measured every $3 \mathrm{~h}$. Controls consisted of $1 \%$ peptone water and were adjusted with $1 \mathrm{M} \mathrm{NaOH}$ to equalize the $\mathrm{pH}$ of the samples. All data points were subsequently blanked against time zero to account for the opacity of the samples. The sample subjected to the lowest OD value was identified as the antimicrobial peptide from the maggots (MAMP), and was used in the subsequent experiments.

Minimum inhibitory concentration (MIC) analysis. The MIC of MAMP was determined by a microdilution assay in 96-well microtiter plates according to the broth microdilution guideline of the Clinical and Laboratory Standards Institute (CLSI) (19). Overnight-cultured S. aureus (ATCC 25923) was diluted with Luria-Bertani (LB) medium to $10^{4}-10^{6} \mathrm{CFU} /$ $\mathrm{ml}$. The bacterial suspension and the serially diluted MAMP were added to 96-well plates at a ratio of 4:1 in a final volume of $100 \mu \mathrm{l}$. The microplates were incubated at $37^{\circ} \mathrm{C}$ with continuous shaking. After $16 \mathrm{~h}$, the optical density at $630 \mathrm{~nm}$ (OD630) was measured with a microplate reader. Vancomycin and penicillin were used as controls. The MIC values were determined at the zero optical density concentration. All experiments were repeated at least three times.

\section{Antimicrobial assays in vivo}

Experimental animals. Female BALB/c mice weighing 18-20 g were provided by the Animal Experimental Center of Dalian Medical University and housed one per cage for one week before study in a room with controlled environment $\left(12 \mathrm{~h} / 12 \mathrm{~h}\right.$ light/dark cycle, $23 \pm 2^{\circ} \mathrm{C}$ and relative humidity $70 \%$ ). They were also given free access to standard laboratory diet and water.

Gel preparation. MAMP was prepared in gel form in $0.5 \%$ hydroxypropylcellulose to a final concentration of $5 \mathrm{mg} / \mathrm{ml}$.

Mouse skin abrasion and infection model. The activity of MAMP against $S$. aureus in vivo was determined according to the method of Cao et al (20) with minor modification. Briefly, mice were injected with $150 \mathrm{mg} / \mathrm{kg}$ of cyclophosphamide 4 days before infection, and with $100 \mathrm{mg} / \mathrm{kg}$ of cyclophosphamide 1 day before infection. After being anesthetized, the dorsal skin of the mice was shaved, and abrasions were produced in a $1 \times 1 \mathrm{~cm}^{2}$ area using a blade. These abrasion wounds damaged only the stratum corneum and the upper layer of the epidermis, but not the dermis. Five minutes later, the wounds were inoculated with $20 \mathrm{ml}$ of $S$. aureus (ATCC 25923) (10 $10^{7}$ CFUs). One group of mice was sacrificed 
$4 \mathrm{~h}$ after infection to control for the infectious dose. Four hours after infection, the wounds of the other mice were smeared with $20 \mathrm{ml}$ of $2.5 \mathrm{mg} / \mathrm{ml}$ MAMP gel or a placebo control gel ( $0.5 \%$ hydroxypropylcellulose). The treatment lasted for 4 days, with two peptide gel applications being performed daily (morning and evening at $8 \mathrm{~h}$ intervals). At the end of the study, the mice were sacrificed, and the wound area of the skin was immediately excised and homogenized. Suitable dilutions of the homogenates were plated on LB plates to determine the number of living bacteria (CFUs).

Histological examination. After the animals were euthanized, biopsy specimens of the excised wound area of the skin were collected and immediately fixed in phosphate-buffered formalin. The biopsy specimens were then embedded in paraffin and stained with hematoxylin and eosin for pathological analysis.

\section{Determination of the antibacterial mechanism}

Membrane permeability. The assay was modified from that of Marri et al (21). S. aureus was grown, washed in PBS and adjusted to a concentration of $1 \times 10^{8}$ CFUs in fresh TSB. Ten microliters of 1x MIC MAMP, $10 \mu \mathrm{l}$ of ortho-nitrophenylgalactoside (ONPG) and $30 \mu \mathrm{l}$ of the bacterial suspension were mixed in triplicate in the wells of a 96-well microtiter plate. Triton X-100 was used as the positive control. Samples were incubated at $37^{\circ} \mathrm{C}$ for $3 \mathrm{~h}$, and the optical density at $405 \mathrm{~nm}$ (OD405) was measured every $30 \mathrm{~min}$.

Observation of the effect of MAMP on S. aureus using scanning electron microscopy (SEM) and transmission electron microscopy (TEM). S. aureus was grown overnight to mid-logarithmic phase and diluted to a final density of $1 \times 10^{8}$ CFUs. The culture was centrifuged at $8,000 \mathrm{x} \mathrm{g}$ for $10 \mathrm{~min}$; the supernatant was removed and $1 \mathrm{ml}$ of 1x MIC MAMP was added to the bacteria, resuspended and cultured at $37^{\circ} \mathrm{C}$ for 6 or $12 \mathrm{~h}$. After centrifuged at $8,000 \mathrm{xg}$ for $10 \mathrm{~min}$ for the second time, the supernatant was removed and the bacteria precipitate was fixed in cold $\left(4^{\circ} \mathrm{C}\right) 2.5 \%(\mathrm{v} / \mathrm{v})$ glutaraldehyde in PBS (0.15 M, pH 7.2) for $24 \mathrm{~h}$, and washed 3 times in PBS at $4^{\circ} \mathrm{C}$. The bacteria were then dehydrated through an ascending series of acetone solutions, critical point dried, placed on aluminium stubs, sputter coated with gold, and then viewed under a field emission scanning electron microscope (JSM-6360LV, Japan). After dehydration, some bacteria were embedded in Epon-Araldite resin mixture, and then cut with an ultramicrotome. The sections were stained with uranyl/lead and viewed under a transmission electron microscope (JEM-2000EX, Japan).

Hemolytic activity. Fresh human blood treated with MAMP was centrifuged at $1,000 \mathrm{x} \mathrm{g}$ for $10 \mathrm{~min}$, and the sediment was washed three times in HEPES ( $\mathrm{pH}$ 7.2) by centrifugation at $1,000 \mathrm{x} \mathrm{g}$ for $10 \mathrm{~min}$. The red blood cells were counted and diluted to a concentration of $10^{7}-10^{8}$ cells $/ \mathrm{ml}$ and then incubated at room temperature for $1 \mathrm{~h}$ with serially diluted MAMP at a ratio of 4:1 in a final volume of $100 \mu 1$. Finally, the OD570 was measured with a microplate reader. $\mathrm{HC}_{50}$ values were obtained according to the method of Cao et al (20). Saline solution at a concentration of $0.85 \%$ was used as the negative control, and $0.1 \%$ Triton $\mathrm{X}-100$ was used as the positive control.

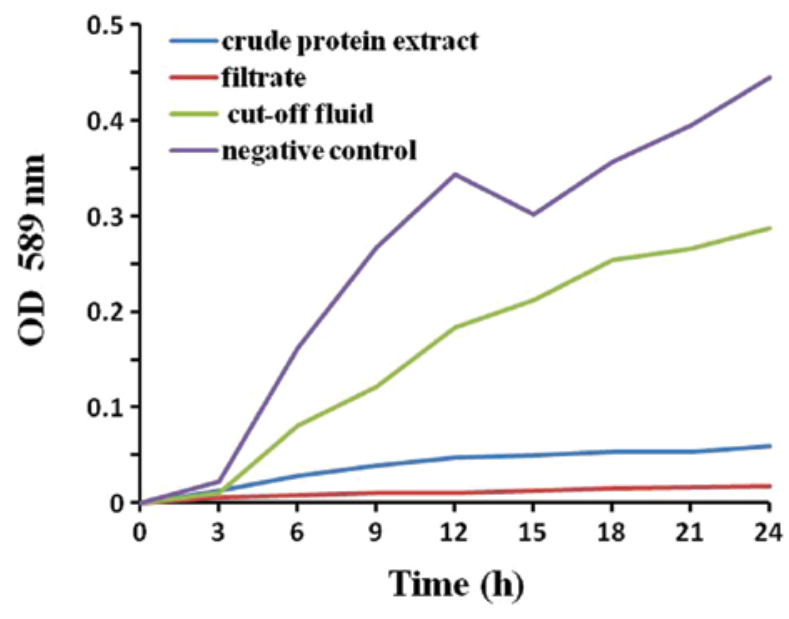

Figure 1. Antibacterial activity of maggot protein components against S. aureus. The filtrate exhibited stronger inhibitory activity, as compared with the crude protein extract from maggots, cut-off fluid and negative control $(\mathrm{P}<0.05)$.

Statistical analysis. All experimental data are expressed as means \pm standard deviation, and the differences among various groups were analyzed by one-way ANOVA and then Fisher's least significant difference t-test, using the SPSS version 13.0 software (SPSS Inc., USA). $\mathrm{P}<0.05$ was considered to indicate a statistically significant result.

\section{Results}

Antimicrobial activity in vitro. A comparison of the sensitivities of the S. aureus strains to protein extracts from maggots was investigated using TB assay. All the test crude protein extract, cut-off fluid and filtrate demonstrated significant antibacterial activity against $S$. aureus, compared with the controls. The crude protein extract and filtrate were more effective than the cut-off fluid, and the filtrate exhibited the strongest inhibitory activity (Fig. 1). Therefore, the filtrate was identified as MAMP and used in subsequent experiments.

The MIC values for MAMP against $S$. aureus are shown in Table I. MAMP showed an MIC value of $25 \mu \mathrm{g} / \mathrm{ml}$ in the standard strains. The MIC values of MAMP were 100 and $200 \mu \mathrm{g} / \mathrm{ml}$ against penicillin-resistance $S$. aureus and MRSA, respectively.

Antimicrobial activity in vivo. The antibacterial activity of MAMP in vivo was determined by an $S$. aureus mouse skin infection model. One group of mice was sacrificed $4 \mathrm{~h}$ after formation of the infected wound, and the viable counts of bacteria on the skin were measured as a control. The other groups were treated and sacrificed 4 days after infection. The bacterial colony counts in the mouse wounds in the MAMP group were lower, when compared with these values in the placebo-treated mice and the untreated mice $(\mathrm{P}<0.05$; Fig. 2$)$.

All of the mice were observed daily. On day 1 after infection, the skin of the mice in the group treated with MAMP showed slight signs of inflammation and was scabbed over (Fig. 3A), while the wounded skin sections of the group treated with placebo were characterized by a small amount of yellow exudates and presented with blistering (Fig. 3B). Additionally, 
Table I. MIC values of MAMP against standard stains and clinically isolated antibiotic-resistant strains of $S$. aureus.

\begin{tabular}{lccc}
\hline & \multicolumn{2}{c}{ MIC $(\mu \mathrm{g} / \mathrm{ml})$} & Penicillin \\
\cline { 2 - 4 } Strains & MAMP & Vancomycin & 6.25 \\
\hline Standard strains & 25 & 3.13 & 12.5 \\
ATCC 25923 & 25 & 3.13 & 6.25 \\
ATCC 29213 & 25 & 3.13 & 10,000 \\
AB 94004 & & & 10,000 \\
Penicillin-resistant strains & 100 & 3.13 & 10,000 \\
12SAU130 & 100 & 6.25 & 20,000 \\
12SAU133 & & & 6.25 \\
Methicillin-resistant strains & 200 & 6.25 & \\
12SAU124 & 200 & & \\
12SAU145 &
\end{tabular}

MIC, minimum inhibitory concentration; MAMP, antibacterial protein from maggots.

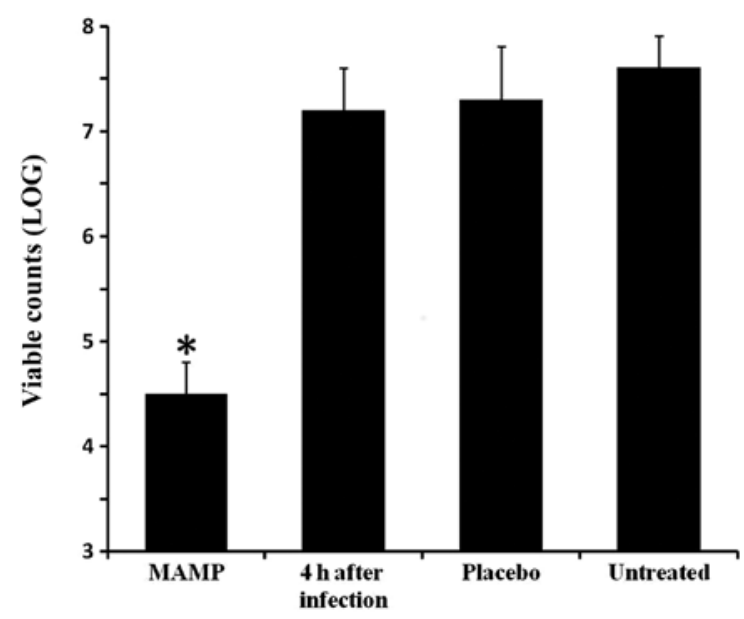

Figure 2. Cutaneous viable counts of surviving $S$. aureus in infected wounds. The antibacterial activity of MAMP in vivo was determined by an $S$. aureus mouse skin infection model. The bacterial colony counts in the MAMP group were lower, as compared with those in the placebo-treated mice and the mice that were untreated. "Compared with $4 \mathrm{~h}$ after infection $(\mathrm{P}<0.05)$.

blisters and light tissue fluid leakage were observed in the wounded skin sections of the untreated mice (Fig. 3C). Four days after infection, the skin in the MAMP group was almost closed, accompanied by a well-defined healing ridge (Fig. 3D). However, the blisters in the group treated with placebo deteriorated and became larger (Fig. 3E). Moreover, the skin sections exhibited a large amount of tissue fluid leakage in the untreated group (Fig. 3F).

Histological observation demonstrated that on day 4 after infection, the wounds treated with MAMP had no sign of infection and collagen fiber was mature and well arranged, with presentation of intact structure. In addition, regenerative folliculus and sebaceous glands were detected in the fibrous connective tissues (Fig. 4A). In contrast, the untreated group and the placebo group lost nearly all of their epidermis, and the dermis was infected to a certain extent (Fig. 4B and C).

\section{Mechanisms of action}

Membrane permeability. The membrane permeability of S. aureus was determined by the optical density values. As shown in Fig. 5, after $30 \mathrm{~min}$ the OD values in the MAMP group and Triton X-100 group were higher than that of the negative control group, indicating that MAMP increased the membrane permeability of $S$. aureus and exhibited a lytic activity against $S$. aureus.

Scanning electron microscopy. SEM indicated that normal $S$. aureus was spherical and mellow in a grape clusterlike arrangement. The surface was smooth with a distinct boundary between the cells (Fig. 6A). After treated with MAMP for $6 \mathrm{~h}, S$. aureus exhibited depressions, and cracks or holes formed on their surface (Fig. 6B). After $12 \mathrm{~h}$, dramatic morphologic changes were noted in S. aureus. The cell membrane of $S$. aureus ruptured, and the contents oozed out from the cells (Fig. 6C).

Transmission electron microscopy. TEM demonstrated that the wall and membrane of normal $S$. aureus were intact (Fig. 6D). After treatment with MAMP for $6 \mathrm{~h}$, S. aureus showed a slight depression (Fig. 6E). After $12 \mathrm{~h}$, the membrane integrity was largely damaged, resulting in the release of the cell content upon cell wall disruption. The residual cell walls showed a bacterial 'ghost' which was displayed as a cavity, indicating the absence of cytoplasmic contents and chromatin silk shift. Edema became widespread, with noticeable gaps between the cell membrane and the cytoplasm (Fig. 6F).

Hemolytic activity. The cytotoxicity of MAMP against mammalian cells was detected by a hemolysis assay. The results demonstrated that MAMP had weak hemolytic activity at a high concentration, and the $\mathrm{HC}_{50}$ value of MAMP was $342 \mu \mathrm{g} / \mathrm{ml}$. At $200 \mu \mathrm{g} / \mathrm{ml}$, the hemolytic activity of MAMP in human erythrocytes was lower than $30 \%$ (Fig. 7). At this concentration, MAMP effectively inhibited the growth of test bacteria, including MRSA. 

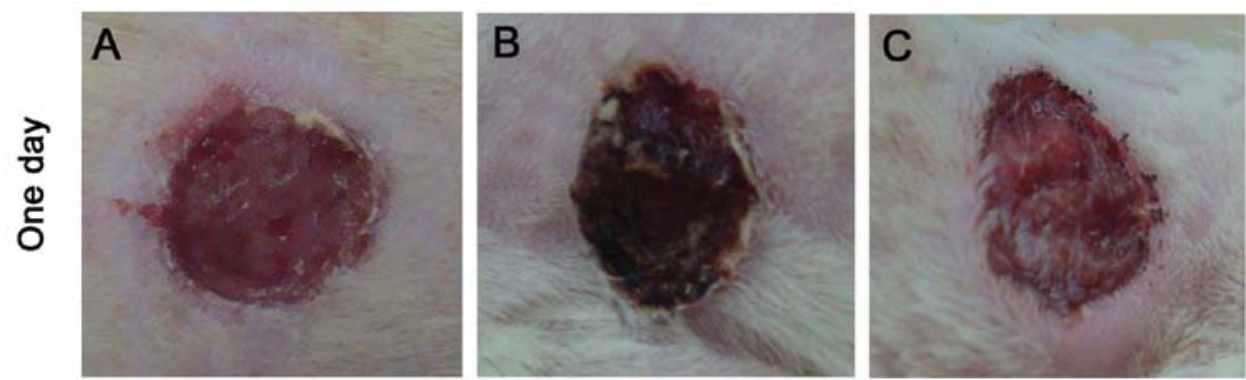

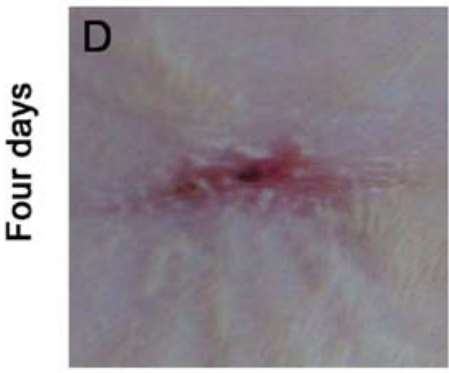

MAMP

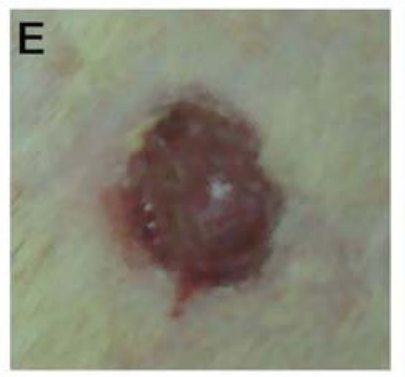

Placebo

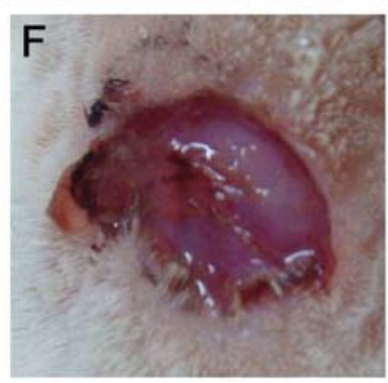

Untreated

Figure 3. Manifestation of infected wounds after treatment with MAMP or placebo or untreated on days 1 and 4. (A) The wound showed a slight inflammatory reaction. (B) Yellow exudates and blisters were observed. (C) There was a small amount of necrotic tissue in the wound bed, other than exudates and blisters. (D) The wound was almost healed with a slight scar. (E) Blisters in the wound deteriorated and became larger. (F) The wound exhibited a great amount of tissue fluid leakage without signs of healing.
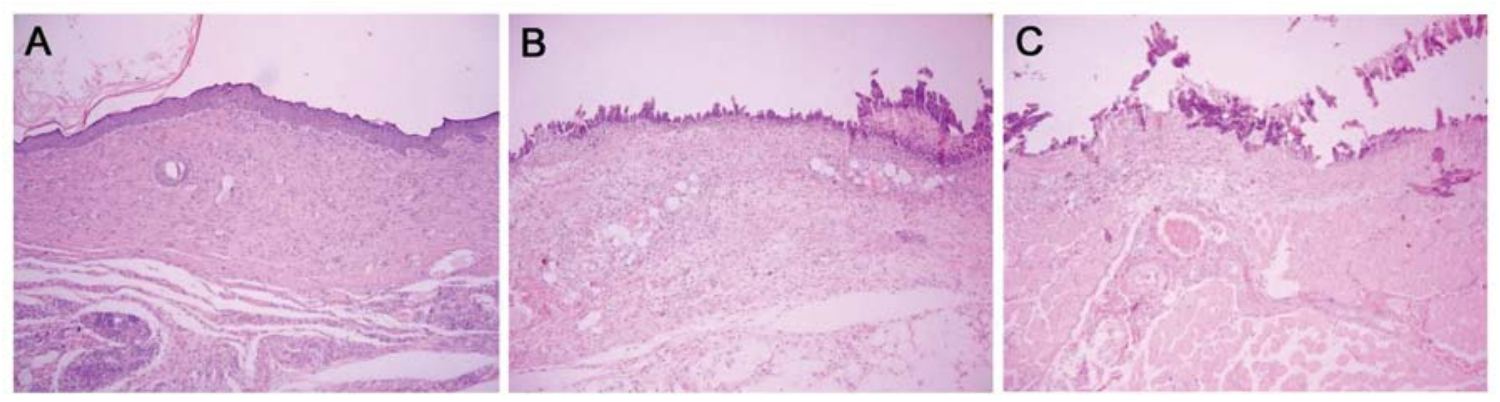

Figure 4. Histological morphologies of the infected wounds in the different groups (H\&E staining; magnification, x100). (A) Intact epidermis, mature collagen fibers and regenerative folliculus and sebaceous glands were detected without signs of infection in the MAMP group. (B) The epidermis was nearly destroyed with necrotic tissue and disorderly arranged collagen fibers in the placebo group. (C) The wound section showed obvious signs of infection, massive necrotic substances and a thin granulation tissue layer without regenerative skin appendages in the untreated group. H\&E, hematoxylin and eosin.

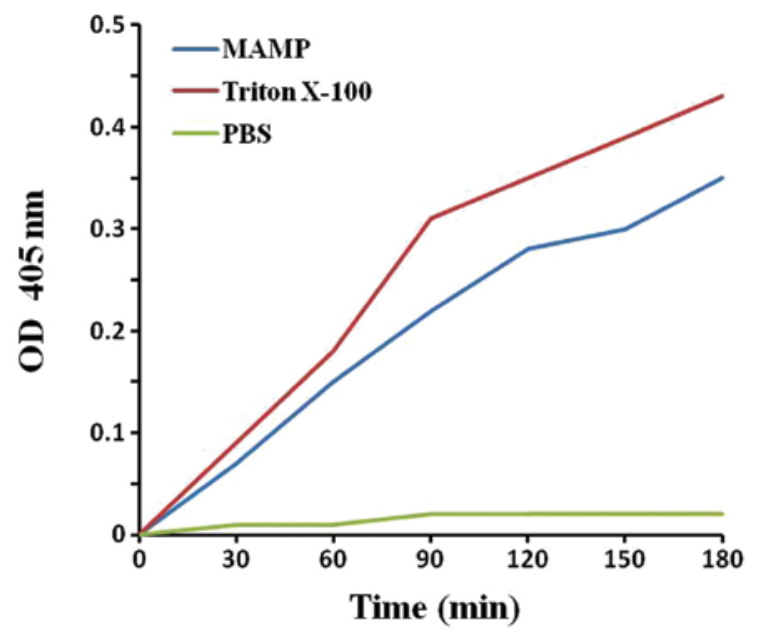

Figure 5. Effects of MAMP on the permeability of the cell membrane of $S$. aureus. The membrane permeability of $S$. aureus was determined by the optical density value. MAMP and Triton X-100 increased the membrane permeability of $S$. aureus, as compared with PBS $(\mathrm{P}<0.05)$.

\section{Discussion}

Maggot therapy, also known as bio-debridement, is a highly successful clinical approach to the treatment of infected wounds. With the rising occurrence of antibiotic-resistant pathogens, maggot therapy has been widely utilized in many countries $(22,23)$. However, little is known concerning the antibacterial mechanisms of maggots, in particular no reports on the mechanism of healing promotion and the effects on the bacterial ultrastructure exist. In the present study, we isolated and purified MAMP using ultrafiltration from the crude protein extract. Based on the TB assay, the filtrate $(<10 \mathrm{kDa})$ exhibited the strongest inhibitory activity and therefore was identified as MAMP. The MIC values also indicated that MAMP effectively inhibited the growth of both standard S. aureus strains and MRSA. The inhibition of standard strains and clinically isolated antibiotic-resistant strains of $S$. aureus was in agreement with previously 

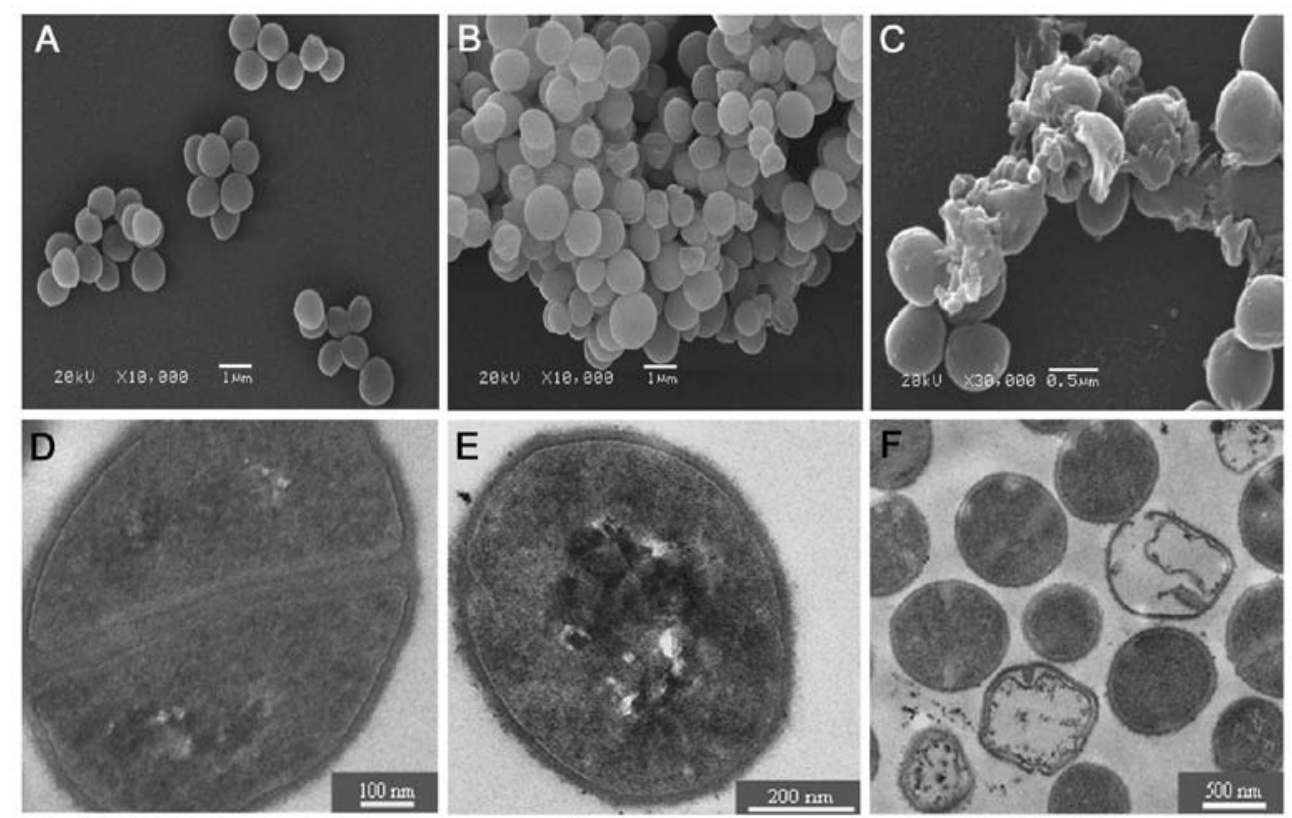

Figure 6. Micrographs of scanning electron and transmission electron microscopy of S. aureus. (A) SEM and (D) TEM indicate normal S. aureus characterized by grape-like clusters, intact membrane and plentiful cytoplasmic contents. After $6 \mathrm{~h}$ of treatment with MAMP, (B) SEM and (E) TEM indicate that S. aureus exhibited slight depressions. After $12 \mathrm{~h}$ of treatment with MAMP, (C) SEM and (F) TEM indicated that S. aureus was obviously damaged with cell wall disruption and release of cell contents. SEM, scanning electron microscopy; TEM, transmission electron microscopy.

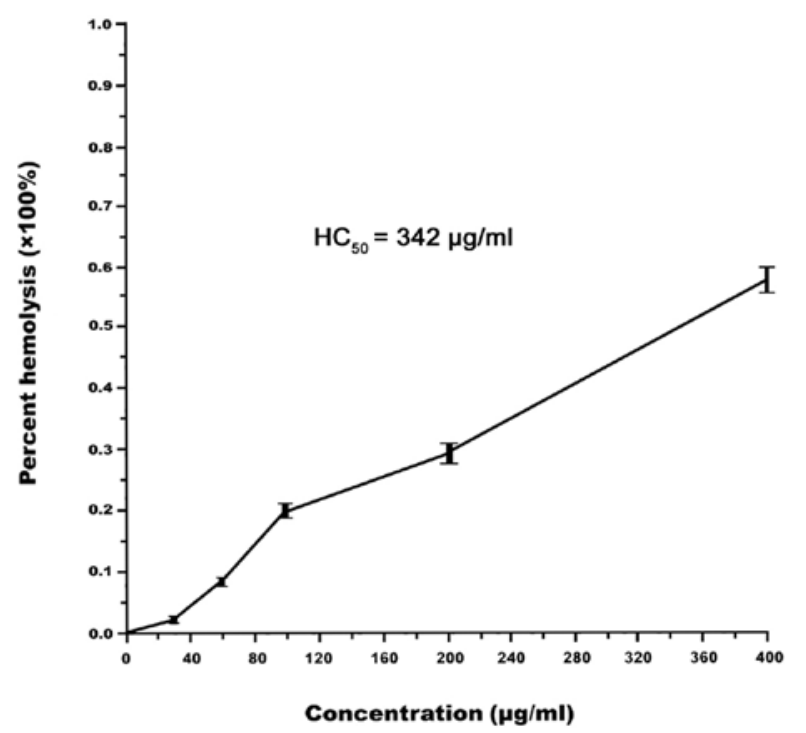

Figure 7. Hemolytic activity of MAMP. The hemolytic activity of MAMP was estimated by monitoring the increase in the absorbance at $570 \mathrm{~nm}$ after incubating human red blood cells with different MAMP concentrations at $37^{\circ} \mathrm{C}$ for $1 \mathrm{~h}$. The positive control was $0.1 \%$ Triton $\mathrm{X}-100$, and $0.85 \%$ saline was used as a blank.

published research, which determined the activity of maggot secretions against bacterial liquid cultures (18). The results obtained in the present study confirmed that the proteins from maggots effective against $S$. aureus were of low molecule weight $(<10 \mathrm{kDa})$. Furthermore, the hemolytic activity of MAMP has always been an obstacle to the application of AMPs in the clinic (24). In our study, the weak hemolytic activity observed in the experimental group demonstrated that MAMP had little influence on normal human cells.
Recently, clinical success of maggot therapy in wound healing has been well documented $(25,26)$. However, little is known about the role of MAMP in infected tissue repair in vivo. In the present study, MAMP prepared in gel $(0.5 \%$ hydroxypropylcellulose) was applied to treat an $S$. aureus mouse skin infection model, and the effect of MAMP upon infected wounds of mice was investigated. At a dosage of 200 times the MIC in vitro, topical application of MAMP resulted in the cure of a wound on the skin of mice infected with $S$. aureus. Significant lower bacterial colony counts were found in the MAMP group, compared with the controls. Based on morphological and histological evaluations, MAMP may have dual functions in the healing process: antibacterial activity and improvement in wound healing quality; the latter was evidenced by well-arranged collagen fibers, mature fusiform fibrocytes, and regenerative folliculus and sebiferous glands as observed in the MAMP group. In addition, the MAMP-treated mice did not show any signs of restlessness or scratching of the wound site, suggesting that MAMP did not cause irritation or pain to the animals. These results in vitro and in vivo imply that MAMP prepared in gel has potential for clinical application to treat wounds infected with S. aureus in a human setting.

Several antimicrobial peptides have been isolated and identified from a variety of organisms (27-30). Their mode of action includes disruption of membranes, interference with metabolism, and the targeting of cytoplasmic components $(31,32)$. Several biolayer interaction and disruption models have been proposed for those AMPs that depend on membrane interference for their antibacterial activity, such as 'barrel-stave pore', 'carpet mechanism', 'toroidal pore' and 'disordered toroidal pore' (33). However, there are no reports concerning the influence of MAMP on the bacterial membrane. In the present study, following the treatment of 
MAMP for $30 \mathrm{~min}$, the membrane permeability of $S$. aureus began to increase. Additionally, SEM and TEM examinations further demonstrated the effects of MAMP on the membrane structure of $S$. aureus, including cell membrane rupture and release of cellular contents.

In conclusion, MAMP with a molecular weight of less than $10 \mathrm{kDa}$, isolated and purified by ultrafiltration, had antimicrobial activities against standard strains and clinically isolated antibiotic-resistant strains of $S$. aureus in vitro and in vivo. The possible mechanism of action included the interaction with the bacterial cell membrane and disruption of the cell surface structure. Our data strongly suggest that MAMP can be developed as a topical therapeutic agent for the treatment of bacterial infections in wound healing.

\section{Acknowledgements}

The present study was supported by grants from the National Natural Science Foundation of China (no. 81270052), from Dalian Scientific and Technological Foundation (no. 2010J21DW022) and from Program for Liaoning Excellent Talents in University.

\section{References}

1. Allen HK, Donato J, Wang HH, et al: Call of the wild: antibiotic resistance genes in natural environments. Nat Rev Microbiol 8: 251-259, 2010.

2. Baer WS: The classic: the treatment of chronic osteomyelitis with the maggot (larva of the blow fly). 1931. Clin Orthop Relat Res 469: 920-944, 2011.

3. Sherman RA: Maggot versus conservative debridement therapy for the treatment of pressure ulcers. Wound Repair Regen 10: 208-214, 2002.

4. Mumcuoglu KY: Clinical applications for maggots in wound care. Am J Clin Dermatol 2: 219-227, 2001.

5. Courtenay M, Church JC and Ryan TJ: Larva therapy in wound management. J R Soc Med 93: 72-74, 2000.

6. Davies CE, Turton G, Woolfrey G, et al: Exploring debridement options for chronic venous leg ulcers. Br J Nurs 14: 393-397, 2005.

7. Wang J, Wang S, Zhao G, et al: Treatment of infected wounds with maggot therapy after replantation. J Reconstr Microsurg 22: 277-280, 2006.

8. Wang SY, Wang JN, Lv DC, et al: Clinical research on the bio-debridement effect of maggot therapy for treatment of chronically infected lesions. Orthop Surg 2: 201-206, 2010.

9. Kerridge A, Lappin-Scott $\mathrm{H}$ and Stevens JR: Antibacterial properties of larval secretions of the blowfly, Lucilia sericata. Med Vet Entomol 19: 333-337, 2005.

10. Huberman L, Gollop N, Mumcuoglu KY, et al: Antibacterial substances of low molecular weight isolated from the blowfly, Lucilia sericata. Med Vet Entomol 21: 127-131, 2007.

11. Bexfield A, Nigam Y, Thomas S, et al: Detection and partial characterisation of two antibacterial factors from the excretions/secretions of the medicinal maggot Lucilia sericata and their activity against methicillin-resistant Staphylococcus aureus (MRSA). Microbes Infect 6: 1297-1304, 2004.

12. Hancock RE and Lehrer R: Cationic peptides: a new source of antibiotics. Trends Biotechnol 16: 82-88, 1998.
13. Gauri SS, Mandal SM, Pati BR, et al: Purification and structural characterization of a novel antibacterial peptide from Bellamya bengalensis: activity against ampicillin and chloramphenicol resistant Staphylococcus epidermidis. Peptides 32: 691-696, 2011.

14. Menzies BE and Kenoyer A: Staphylococcus aureus infection of epidermal keratinocytes promotes expression of innate antimicrobial peptides. Infect Immun 73: 5241-5244, 2005.

15. Knobloch JK, Horstkotte MA, Rohde H, et al: Evaluation of different detection methods of biofilm formation in Staphylococcus aureus. Med Microbiol Immunol 191: 101-106, 2002.

16. Lowy FD: Staphylococcus aureus infections. N Engl J Med 339: 520-532, 1998.

17. Bradford MM: A rapid and sensitive method for the quantitation of microgram quantities of protein utilizing the principle of protein-dye binding. Anal Biochem 72: 248-254, 1976.

18. Thomas S, Andrews AM, Hay NP and Bourgoise S: The antimicrobial activity of maggot secretions: results of a preliminary study. J Tissue Viability 9: 127-132, 1999.

19. Hou Z, Lu J, Fang C, et al: Underlying mechanism of in vivo and in vitro activity of $\mathrm{C}$-terminal-amidated thanatin against clinical isolates of extended-spectrum beta-lactamase-producing Escherichia coli. J Infect Dis 203: 273-282, 2011.

20. Cao L, Dai C, Li Z, et al: Antibacterial activity and mechanism of a scorpion venom peptide derivative in vitro and in vivo. PLoS One 7: e40135, 2012.

21. Marri L, Dallai R and Marchini D: The novel antibacterial peptide ceratotoxin A alters permeability of the inner and outer membrane of Escherichia coli K-12. Curr Microbiol 33: 40-43, 1996.

22. Dumville JC, Worthy G, Bland JM, et al: Larval therapy for leg ulcers (VenUS II): randomised controlled trial. BMJ 338: b773, 2009.

23. Whitaker IS, Twine C, Whitaker MJ, et al: Larval therapy from antiquity to the present day: mechanisms of action, clinical applications and future potential. Postgrad Med J 83: 409-413, 2007.

24. Levy O: Antimicrobial proteins and peptides: anti-infective molecules of mammalian leukocytes. J Leukoc Biol 76: 909-925, 2004.

25. Davydov L: Maggot therapy in wound management in modern era and a review of published literature. J Pharm Pract 24: 89-93, 2011.

26. Opletalová K, Blaizot X, Mourgeon B, et al: Maggot therapy for wound debridement: a randomized multicenter trial. Arch Dermatol 148: 432-438, 2012.

27. Steiner H, Hultmark D, Engström A, et al: Sequence and specificity of two antibacterial proteins involved in insect immunity. Nature 292: 246-248, 1981.

28. Cole AM, Weis P and Diamond G: Isolation and characterization of pleurocidin, an antimicrobial peptide in the skin secretions of winter flounder. J Biol Chem 272: 12008-12013, 1997.

29. Park CB, Lee JH, Park IY, et al: A novel antimicrobial peptide from the loach, Misgurnus anguillicaudatus. FEBS Lett 411: 173-178, 1997.

30. Nelson A, Hultenby K, Hell E, et al: Staphylococcus epidermidis isolated from newborn infants express pilus-like structures and are inhibited by the cathelicidin-derived antimicrobial peptide LL37. Pediatr Res 66: 174-178, 2009.

31. Brogden KA: Antimicrobial peptides: pore formers or metabolic inhibitors in bacteria Nat Rev Microbiol 3: 238-250, 2005.

32. Yang L, Weiss TM, Lehrer RI, et al: Crystallization of antimicrobial pores in membranes: magainin and protegrin. Biophys $\mathbf{J}$ 79: 2002-2009, 2000.

33. Melo MN, Ferre R and Castanho MA: Antimicrobial peptides: linking partition, activity and high membrane-bound concentrations. Nat Rev Microbiol 7: 245-250, 2009. 